\title{
Dynamics of a Limecola (Macoma) balthica population in a tidal flat area in the western Wadden Sea: effects of declining survival and recruitment
}

\author{
J. J. Beukema ${ }^{1 *}\left(\mathbb{D}\right.$, R. Dekker ${ }^{1,2}$ and J. Drent ${ }^{1,2}$
}

\begin{abstract}
We followed the dynamics of the population of the bivalve Limecola (Macoma) balthica in the westernmost part of the Wadden Sea by monitoring for 44 years (1973-2016) its numbers and age composition at 15 sites in a 50-km² tidal-flat area. During the first half of this period, the annual recruitment and adult survival were at a relatively constant level, resulting in rather constant numbers. During the second half of the observation period, annual recruitment and adult survival showed declining trends, resulting in seriously reduced adult abundance. Sudden substantial reductions in adult survival started around 1996 at a few sites to spread over the entire area within 5 years, like an infectious disease. The resulting small adult stocks produced small numbers of recruits. The stock-recruitment curve showed an increasing part up to about 30 adults $\mathrm{m}^{-2}$, followed by invariably successful recruitments at $>40$ adults $\mathrm{m}^{-2}$. Both recruitment and adult survival were negatively related to water temperatures. However, elevated temperatures after 1997 could not explain the very low survival rates observed after 1996 and the very low recruitment success after 2003. So far, recovery of the population has hardly taken place, with both recruitment and adult survival at lower levels than observed for the initial stable period.
\end{abstract}

Keywords: Climate change, Long-term data, Population dynamics, Disease, Stock-recruitment relationship

\section{Introduction}

In the field, population sizes usually vary strongly with time. It is one of the major challenges of ecological research to unravel causes of this variability by studying underlying processes such as recruitment and subsequent survival. A prerequisite for such investigations is the availability of prolonged (and preferably uninterrupted) series of consistently gathered data. In the Balgzand tidal flat area in the westernmost part of the Wadden Sea, populations of benthic animals have been monitored ever since the early 1970s. The available data set includes twice-annual estimates of the numerical density of the various age groups present of the tellinid

\footnotetext{
*Correspondence: jan.beukema@nioz.nl

${ }^{1}$ Royal Netherlands Institute for Sea Research, P.O. Box 59, 1790 AB Den Burg, Texel, The Netherlands

Full list of author information is available at the end of the article
}

bivalve Limecola balthica. This $>40$ years long data series allows annual estimates of recruitment as well as survival of this species in an area of $50 \mathrm{~km}^{2}$.

Data on L. balthica abundance from other areas are available only for much shorter periods [1: 10 years; 2 : 18 years] and lack separate data of recruitment and survival. Other available data series are interrupted by long periods without data [3: three short periods in the 1930, 1940 and 1980s; 4: three short periods in the 1930, 1970 and 2000s]. As bivalve abundance in any year is heavily influenced by recruitment success in the same and preceding years, conclusions on long-term trends from interrupted series are not so accurate. The authors dealing with these interrupted series realized the high variability in annual recruitment and the positive influence of cold winters on recruitment success. This relationship was analyzed by Beukema and Dekker [5], showing that the near-absence of predators (shrimps and shore crabs) 
on the early benthic stages of bivalves in springs on tidal flats after cold winters allowed the survival of high numbers of bivalve spat.

The Wadden Sea is located in the warmer southern part of the distribution area of L. balthica [6]. In this area its populations appear to be vulnerable to temperature rise, evidenced by reduced reproductive output, recruitment, and survival in years that were warmer than average [7]. Nowadays, water temperatures in the Wadden Sea show a warming long-term trend and are by about $1.5{ }^{\circ} \mathrm{C}$ higher than half a century ago [8]. The declining trend of occurrence of cold winters after 1997 (and the complete absence of really severe winters for the last 2 decades) might have resulted in declining trends in survival and recruitment of $L$. balthica $[7,9]$ and thereby a decline in the abundance of this species.

L. balthica is an important prey for some species of wading birds, in particular Red Knots Calidris canutus. The serious decline of the L. balthica populations in the Wadden Sea raised concern of nature conservationists. They tend to attribute the decline to negative effects of fishery for cockles and mussels [2, 10]. On Balgzand, however, this fishery ended already in the early 1990s, whereas the strong population declines only started in the late 1990s. Therefore, another explanation is needed.

The aim of the present study is to analyze the underlying causes of the long-term dynamics of the size of the adult population of $L$. balthica in the monitored area. In other words: were the changes in numbers of adult $L$. balthica governed in the first place by variability in their annual recruitment, in annual survival of their adults or in both. The main hypothesis is that the temperature increase was a main cause of the long-term decline of $L$. balthica abundance by declined recruitment and survival. We investigate whether the temperature-caused declines were sufficient to explain the population collapse.

\section{Methods}

\section{Study area}

The data on $L$. balthica numbers were obtained as part of a long-term program involving twice-annual sampling ever since the 1970s of the macrozoobenthic animals at 15 permanent sampling stations located on Balgzand (Fig. 1), a $50 \mathrm{~km}^{2}$ tidal flat area in the westernmost part of the Wadden Sea (at about $53^{\circ} \mathrm{N}$ and $5^{\circ} \mathrm{E}$ ). Further details on the sampling area, the stations, and the methods can be found in [11].

\section{Bivalve sampling}

Along each of the 12 transects of $1 \mathrm{~km}$ length (numbered 1-12 in Fig. 1), 50 cores were taken twice-annually at equal intervals to a depth of about $30 \mathrm{~cm}$. In FebruaryMarch, when cores of nearly $0.02 \mathrm{~m}^{2}$ (15.6 cm diameter) were used, the sampled area per transect covered a total of $0.95 \mathrm{~m}^{2}$. In August-September, using cores of nearly $0.01 \mathrm{~m}^{2}$ (10.7 cm diameter), $0.45 \mathrm{~m}^{2}$ were covered per transect. Cores used in winter were larger because of the smaller numbers of animals in that season. At each of 3 additional square sampling sites (A, B, and C in Fig. 1), samples of about $1 \mathrm{~m}^{2}$ were collected in the same months.

Bivalves were sorted from the sieved (1-mm mesh size) samples, assigned (by counting year marks on the shell) to age classes (cohorts were indicated by the year of birth), and counted. Numerical densities were expressed in $\mathrm{nm}^{-2}$ and presented as 15 -station means.

Recruitment (numerical density of a new cohort) was assessed for the first time in their life in late-summer at an age of about 0.3 year after the start of their benthic life and again half a year later in late-winter. At that time the animals were still of spat size (mostly $<7 \mathrm{~mm}$ shell length) and aged about 0.8 year. For some purposes, these early estimates were not sufficiently precise: due to the small size of part of the spat an unknown proportion passed the sieves or were overlooked at sorting. In a few years, when spat of $<1 \mathrm{~mm}$ shell length predominated, cohort densities were even found to be larger at an age of 1.3 years than at younger ages. Therefore, recruitment magnitude was also expressed as cohort density at an age of 1.3 years. Because of the extreme variability in recruitment success (3 orders of magnitude), recruit densities were plotted and evaluated after ${ }^{10} \log$ transformation.

Annual survival of adults was expressed as the percentage of the numbers of 1.8 or more years old individuals in a certain year that were still alive 1 year later: 100 . $\left(\mathrm{nm}^{-2}\right.$ of $2.8^{+}$years-olds in year $\mathrm{n}+1 / \mathrm{nm}^{-2}$ of $1.8^{+}$yearsolds in year $\mathrm{n}$ ). Late-winter assessments of density were used, because transect samples were larger in late winter than in late summer, allowing more precise estimates of annual survival. We calculated survival percentages separately for each of the 15 sampling sites, but for average total-Balgzand estimates we excluded estimates at sites $\mathrm{C}$ and 12 , because adult densities were invariably low there, not allowing sufficiently precise survival estimates. For this reason, we did not use site- percentages that were based on numbers of $1.8^{+}$years-olds of less than $20 \mathrm{~m}^{-2}$.

\section{Results}

\section{Annual recruitment}

The half-yearly sampling program yielded data on annual spat abundance $\left(\mathrm{n} \mathrm{m}^{-2}\right)$ in late summer $(0.3$ year after the start of benthic life) and late winter (at an age of 0.8 year). These two data series (solid squares and open circles in Fig. 2) revealed highly significant declining trends in ${ }^{10} \mathrm{log}$ $\mathrm{nm}^{-2}: \mathrm{r}^{2}=0.48$ and $\mathrm{r}^{2}=0.27, p<0.0001$ and $p<0.001$ $(\mathrm{n}=44)$ for spat abundance at ages of 0.3 and 0.8 year, respectively. The two series were strongly correlated 


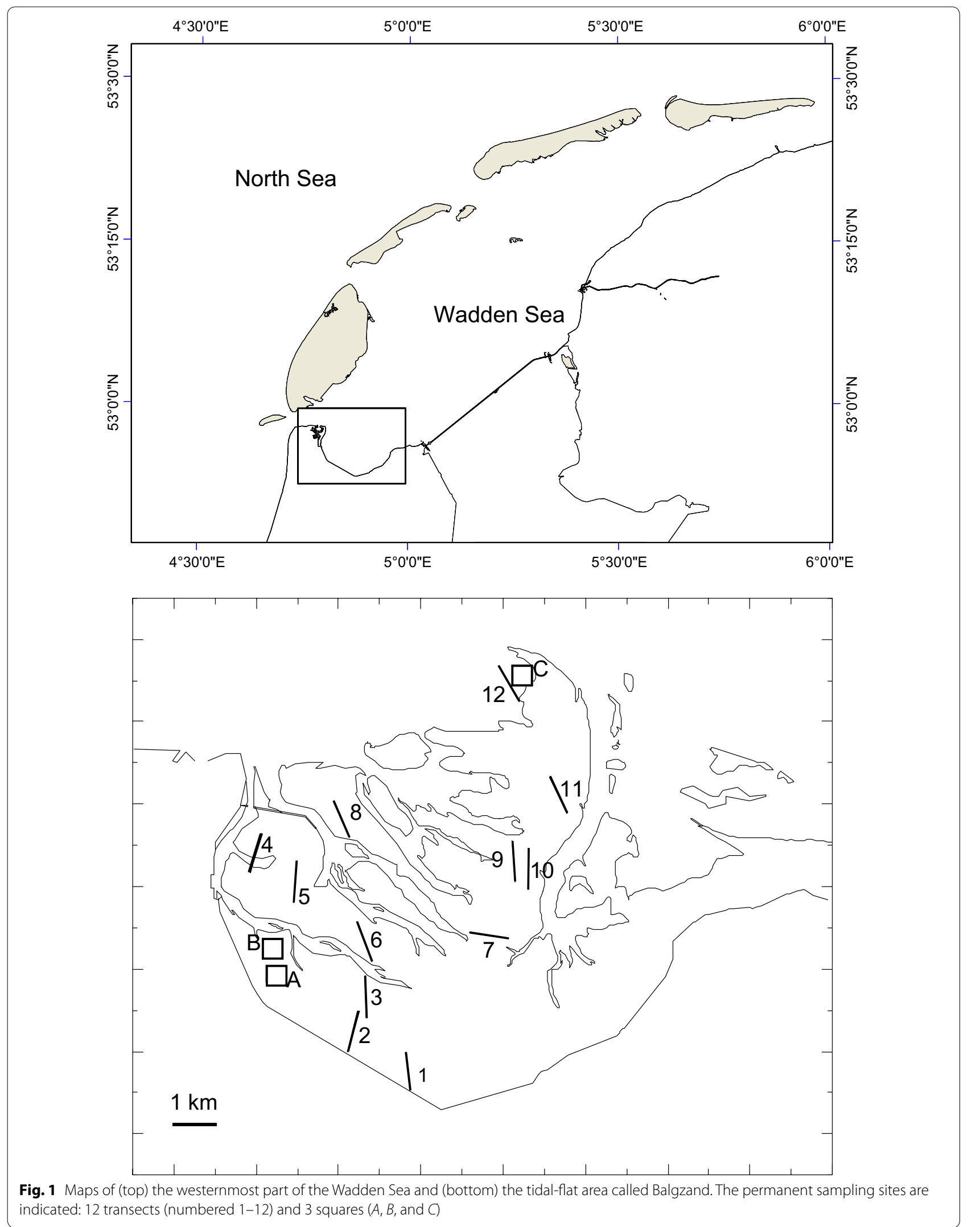




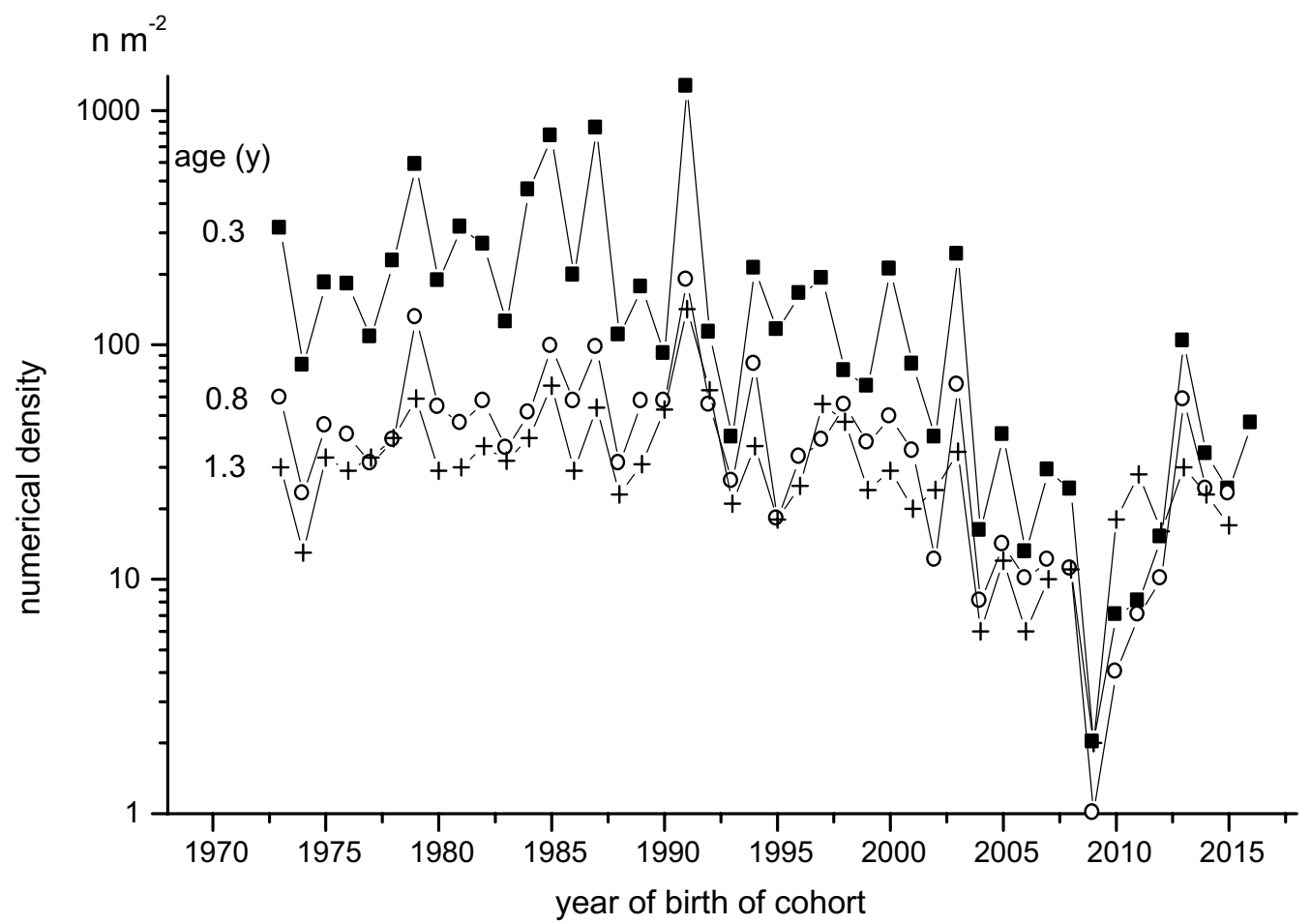

Fig. 2 Long-term (1973-2016) data series of biannual (late winter and late summer) estimates of Limecola balthica recruit densities on Balgzand, in $\mathrm{nm}^{-2}$ (means of 15 sampling sites). Densities assessed at three ages of the recruits of each cohort: (solid squares) in summer at an age of 0.3 year, (open circles) in winter at an age of 0.8 year, and (crosses) in summer at an age of 1.3 years

$\left(r^{2}=0.81, p<0.0001\right)$. Usually, spat numbers of the same cohort had substantially declined after their first winter, on average by some $75 \%$. Further declines (after reaching an age of 0.8 year) were smaller: numbers at an age of 1.3 years (crosses in Fig. 2) were on average only about $25 \%$ smaller than at 0.8 year. There were, however, a few notable exceptions, namely in cohorts born in the 20092012 period (compare Fig. 2: crosses situated well above open points in 2010 and 2011). In these 2 years, nearly all spat individuals (aged 0.3 or 0.8 year) were unusually small, most likely partly passing the sieves used. After the second growing season, at an age of 1.3 years, they were large enough to be fully retained by the sieves and probably also completely detected at sorting. This occurred in only two out of 44 years of observation.

The 44-y long data series of 1.3-year-olds nevertheless showed strong correlations with those of 0.3 - and 0.8 -year-olds $\left(\mathrm{r}^{2}=0.71\right.$ and $0.79, p<0.001$ and $<0.0001$, respectively). Like the estimates at the younger ages of 0.3 and 0.8 year, densities of 1.3-year-olds showed a declining long-term trend (crosses in Fig. $2 ; \mathrm{r}^{2}=0.17, \mathrm{n}=44$, $p<0.01)$.

Note that declining trends in recruitment were totally absent in all three data series of Fig. 2 till the early 2000s. The most recent strong cohort (with
$>200$ of 0.3 -year-olds $\mathrm{m}^{-2}$ ) was born in 2003. Thereafter, trends in annual recruitment were dramatically declining till a low point in 2009. The latter decline was behind the significant declines found for the entire 44-year periods. Only during the 2013-2016 period, recruitment approached the original level of the 1970 and 1980s.

\section{Annual adult survival}

As counts of numbers at an age of 1.3 years provided the first reliable estimate of abundance in all cohorts, we had to use the density values of $>1.3$-year-olds (in practice: $1.8^{+}$years, see Methods) as initial abundance to estimate subsequent annual survival (late-winter to late-winter one year later).

During the first half (1974-1995) of the 44-year period of observation, mean annual survival rates of adult $L$. balthica were rather constant at a level of around 65 or $70 \%$ year $^{-1}$ (horizontal lines in Fig. 3b). Thereafter, survival rates became lower to reach for a prolonged period (1999-2009) a level of less than half of the initial rates. Only by 2010, annual survival was high again for a few years, but not consistently so in subsequent years, as it appeared to stabilize at a level of about $40 \%$ in the most recent years (2013-2015). 

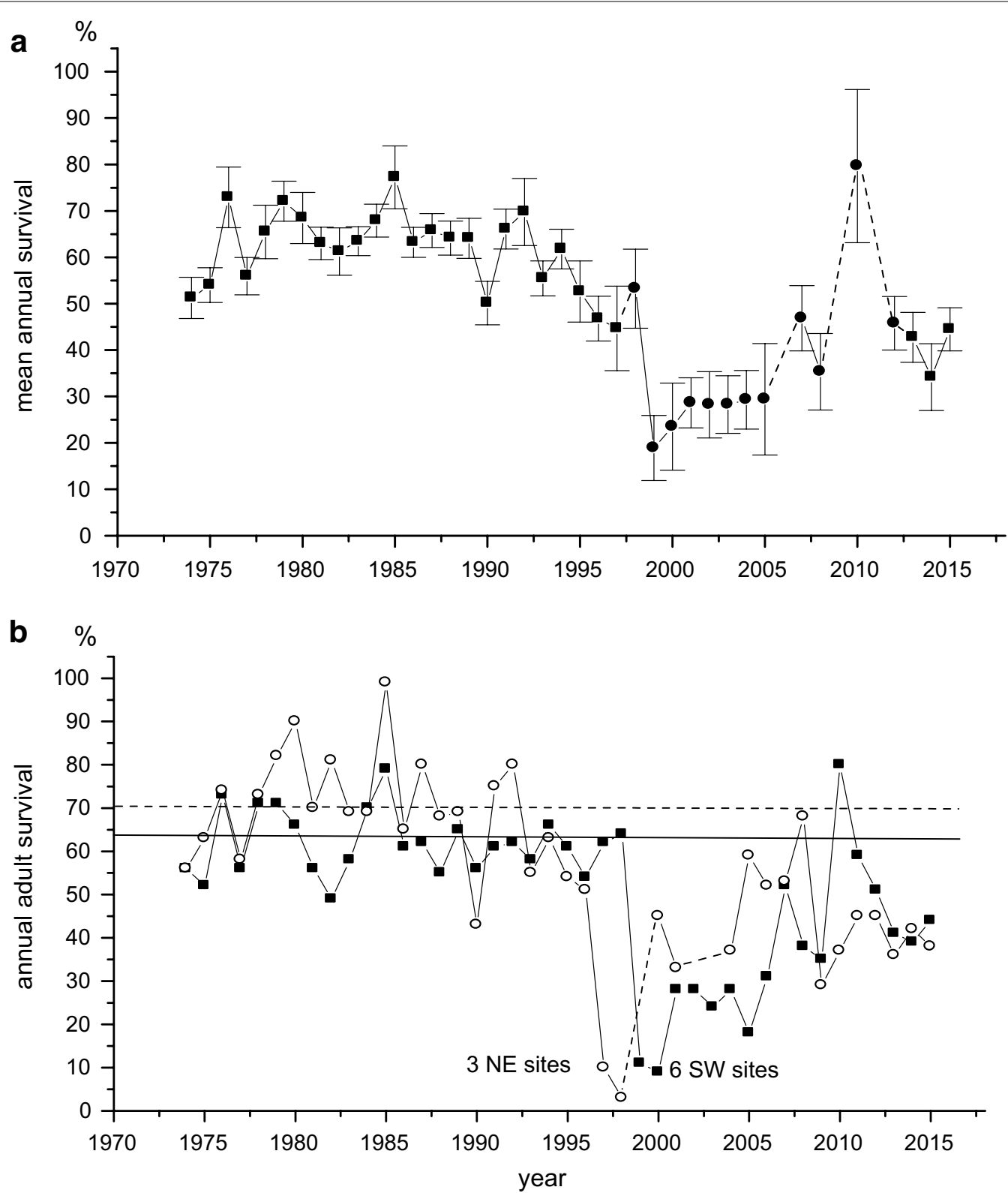

Fig. 3 Long-term (1974-2015) data series on annual survival rates (in \% of initial $\mathrm{nm}^{-2}$, assessed in late winter) of adult (at least 1.8 years old) Limecola balthica on Balgzand. a Means with 1 SE of 5-13 estimates at the separate sampling sites with sufficient data (squares: $\mathrm{n}=12$ or 13 ; circles: $\mathrm{n}=5-9$; years with $\mathrm{n} \leq 3$ omitted); b Mean percentages shown separately for (open circles) a group of 3 sites in the NE part of Balgzand (numbered 9, 10, and 11 in Fig. 1) where reduced survival started in 1997, and (solid squares) a group of 6 sites in the SW half of Balgzand (numbered 2, 3, 4, 5, A, and B in Fig. 1) where reduced survival started in 1999 (compare Fig. 4). The horizontal lines indicate the long-term mean values for the first half (1974-1995) of the period of observation, full line for the 6 SW sites, dashed line for the 3 NE sites

During the first half of the observation period, annual survival rates did not strongly vary between sampling sites; see the relatively narrow range of the standard errors (Fig. 3a). Substantial between-site differences in survival started to appear in 1995 , when the survival rate at site 7 dropped from values in earlier years of between 35 and $68 \%$ to only $7 \%$ year $^{-1}$. At the other 12 sites, survival in 1995 amounted to values between 31 and $106 \%$, with an average of $56 \%$ year $^{-1}$. In the 5 years after 1995 , low (i.e. $<30 \%$ year $^{-1}$ and frequently even $<10 \%$ year $^{-1}$ ) survival rates started to occur at other sites as well (Fig. 4): at one site in 1996, at three neighboring sites in 1997 (open points in Fig. 3b), at one more site in 1998, at no less than six neighboring sites in 1999 


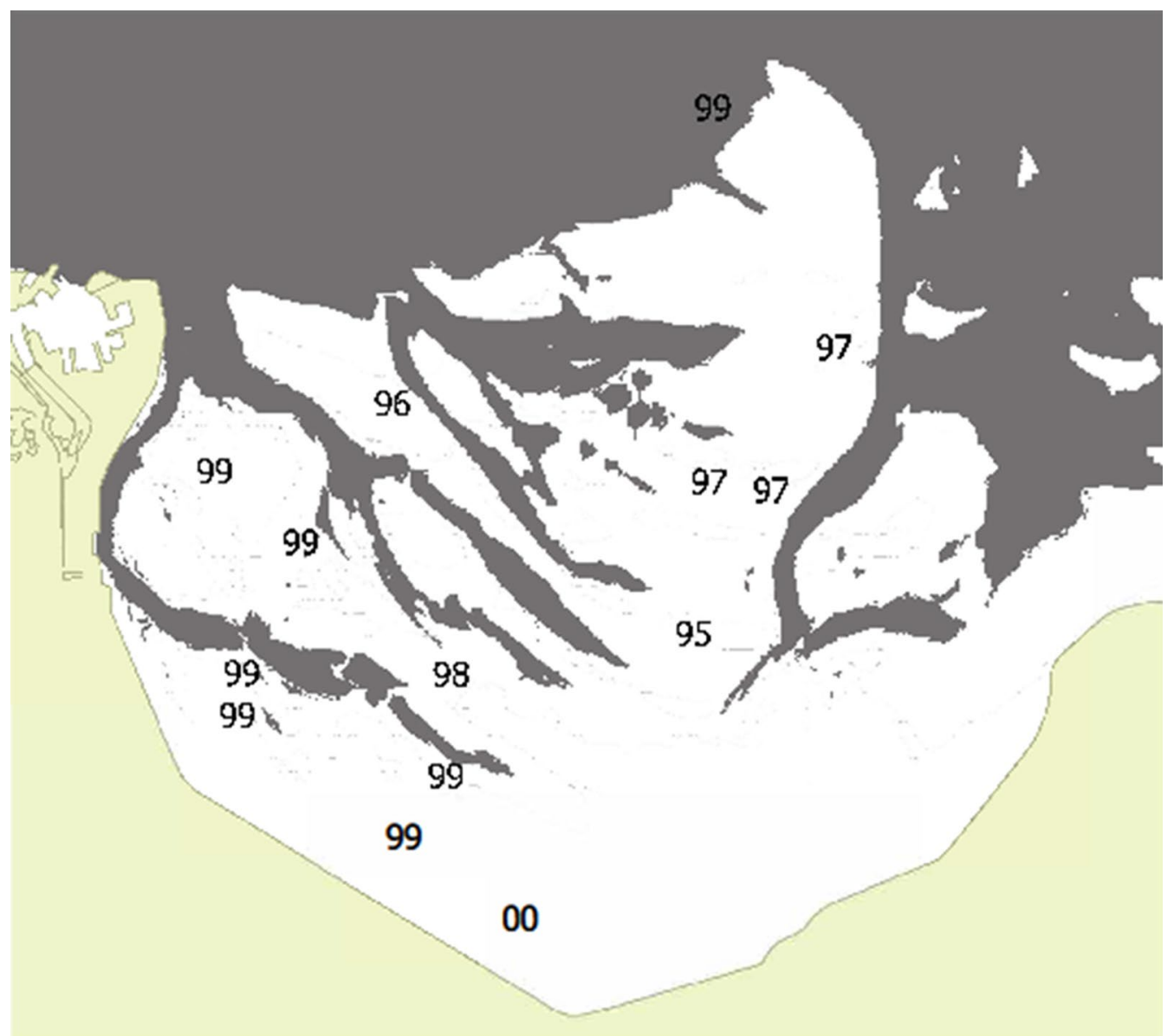

Fig. 4 Map of Balgzand showing the sequence of appearance of strongly reduced (from around 60 to $<30 \%$ year ${ }^{-1}$ ) annual survival of adult Limecola balthica. Appearances in successive years indicated by date. First appearance in 1995 in the southeastern part of the area (site 7), last site affected in 2000 at the southernmost sampling place (site 1)

(solid points in Fig. 3b). Only by 2000, low survival rates reached the last remaining site (numbered 1 in Fig. 1 and 00 in Fig. 4).

The gradual spread of the occurrence of sudden drops in adult survival over the Balgzand area, as shown in Fig. 4, points to a more rapid transfer in a northwestsoutheast than in a northeast-southwest direction. Note in Fig. 4 the short (one-year) time lags between sites 7 and 8 (1995-1996), site 8 and sites 9, 10 and 11 (19961997), sites 2, 3, 4, 5, A and B and site 1 (1999-2000) versus the longer time lags ( 2 or more years) between site 7 and site 6 (1995-1998), between sites 9, 10 and 11 and sites 12 and $C$ (1997-1999) or between site 7 and site 1 (1995-2000) that are just as well pairs of geographically adjacent sites. The main tidal gullies in the Balgzand area are shown in Fig. 4 and run for by far the greater part in northwest-southeast directions. Main water mass movements over the Balgzand area follow these directions, both during flood and ebb tides [12].

\section{Temperature influence on recruitment and survival}

Both recruitment and adult survival were higher in years starting with relatively low than high water temperatures (Fig. 5). To account for the above periods of severely reduced survival and recruitment, data in this Figure are separately indicated for the three periods: (closed squares) high survival and recruitment, (open circles) low survival and high recruitment, and (crosses) low survival and low recruitment. Statistically significant negative relationships were found for the relations between water temperature with recruitment (at an age of 0.3 year) for the 1973-1994 and the 1973-2004 periods (solid and broken lines, respectively, in Fig. 5a) and with survival for the 1973-1994 period (Fig. 5b). For recruitment assessed at an age of 1.3 years, the relationship was again negative and just significant: $\log \mathrm{R}=1.67-0.04 \mathrm{~T}, \mathrm{r}^{2}=0.12$, $\mathrm{n}=31, p=0.05$. For the 12 years of the 2004-2015 period with mostly very low recruitment, the relationship with temperature happened to be positive and was just 

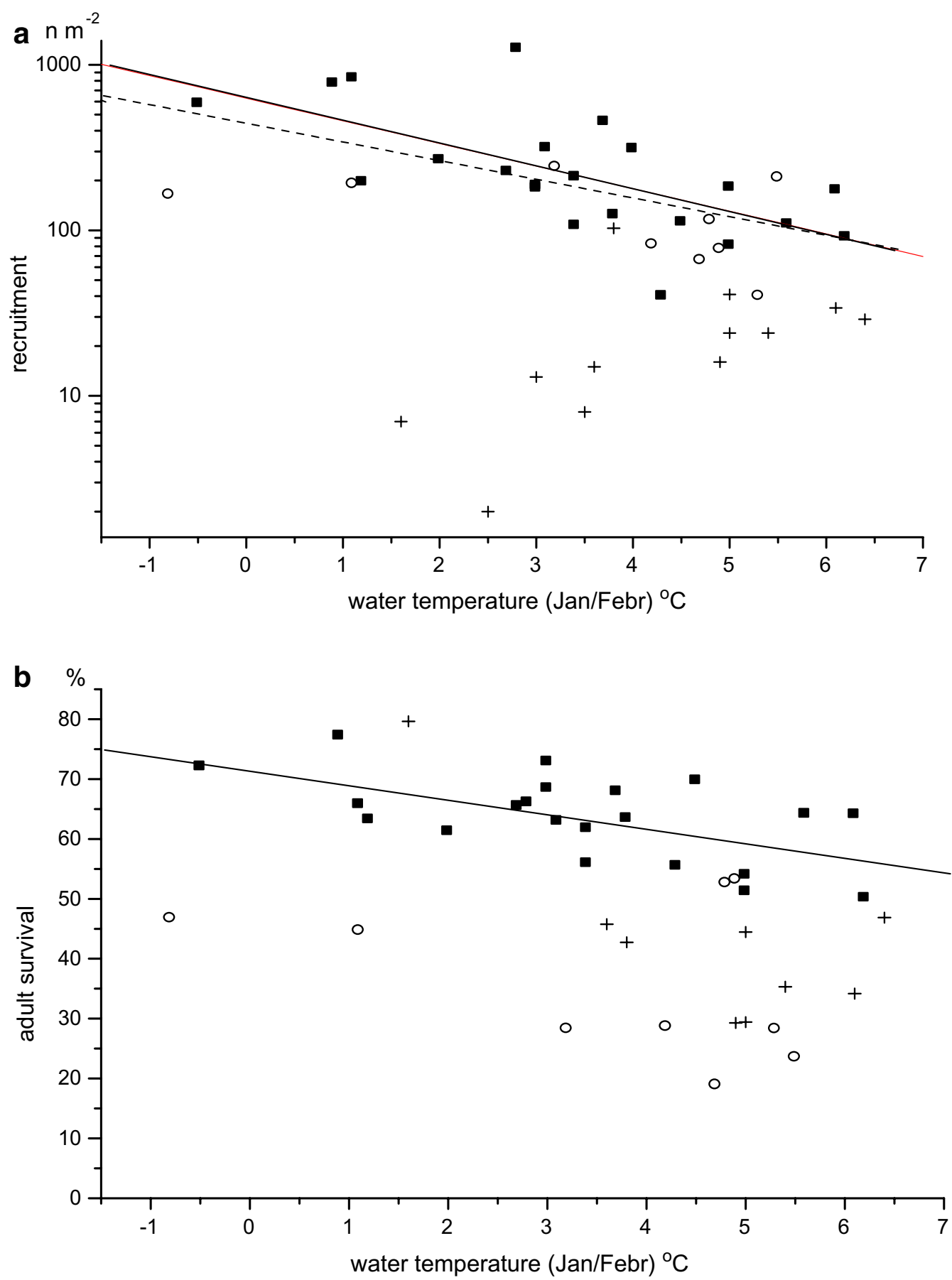

Fig. 5 Limecola balthica. Relationships between water temperatures $\mathrm{T}$ in winter (means of January and February, in ${ }^{\circ} \mathrm{C}$ ) and $\mathbf{a}$ recruitment $\mathrm{R}$ in the subsequent summer ( $\mathrm{nm}^{-2}$ of 0.3 -year-olds) and $\mathbf{b}$ survival $\mathrm{S}$ of adults in the subsequent year (in \% of numbers in March). Means of data collected at 15 (b: 13) sampling sites. One point for each of 43 years; periods indicated: (solid squares) 1973-1994, (open circles) 1995-2003, and (crosses) 2004-2015. Lines show best fits for the points of the 21/22 years of the 1973-1994 or 31 years of the 1973-2003 period: a (solid line, closed squares) ${ }^{10} \log R=2.80-0.14 \mathrm{~T}, r^{2}=0.42, n=22, p<0.01 ;$ (dashed line, closed squares + open circles) ${ }^{10} \log R=2.64-0.11 \mathrm{~T}, \mathrm{r}^{2}=0.32, \mathrm{n}=31, p<0.001 ; \mathbf{b}$ (closed squares) $\mathrm{S}=71.4-2.35 \mathrm{~T}, \mathrm{r}^{2}=0.35, \mathrm{n}=21, p<0.01$ 
significant for spat of 0.3 year old $(\log \mathrm{R}=0.5+0.18 \mathrm{~T}$, $\left.\mathrm{r}^{2}=0.38, \mathrm{n}=12, p=0.03\right)$, but far from significant for 1.3-year olds $\left(\mathrm{r}^{2}=0.03, \mathrm{n}=12, p=0.6\right)$.

The data shown in Fig. 5 clearly indicate that (1) recruitment was in all of the years of the 2004-2015 period (crosses) far below values to be expected from the winter-temperature versus recruitment relationship (lines) observed in earlier years (Fig. 5a), and (2) adult survival was in all of the years of the 1995-2003 (open circles) and most of the later years (crosses) far below values to be expected from the winter-temperature versus survival observed in earlier years (Fig. 5b).

\section{Population size at reduced recruitment or survival}

The size of the adult population of $L$. balthica on Balgzand declined dramatically between the first and second half of the period of observation, from densities between 50 and $100 \mathrm{~m}^{-2}$ up to 1996 to around $10 \mathrm{~m}^{-2}$ in the 2000s (solid points in Fig. 6). To investigate whether reductions in recruitment or in adult survival were the prime cause of this decline, we calculated for each year the expected adult density at either constant recruitment (and observed survival) in all years or constant adult survival (and observed recruitment). As a constant recruitment value we took a density of 38 individuals $\mathrm{m}^{-2}$ of 1.3-year-olds, being the mean density of this age group of the 32 cohorts born in the 1972-2003 period, i.e. before the serious decline of annual recruitment (Fig. 2). As a constant adult survival rate we took $65 \%$ year $^{-1}$, being the mean value for the first half of the period of observation, before the serious decline in survival (Fig. 3). Using both of these constants, the density of adults $\left(2.3^{+}\right.$-yearolds) would amount to $71 \mathrm{~m}^{-2}$ in each year (horizontal lines in Fig. 6).

The observed numbers of adults included in Fig. 6 (solid points) are averages of the numbers found at the 15 sampling sites. Standard errors of these averages, reflecting spatial variation, generally amounted to $10-15 \%$ of the averages and were higher (up to about 30\%) only in the years between 1995 and 2001, when only part of the sampling sites were struck by the excessive mortality. Statistically significant differences between observed and expected numbers were (nearly) absent in the years before 1999 in Fig. 6a and before 2006 in Fig. 6b. Long periods with consistently highly significant differences (i.e. differences exceeding several times the standard errors) were observed for the years 1999-2009 in Fig. 6a and the years 2006-2016 in Fig. 6b.

Expected numerical adult densities at constant survival and real recruitment values (open points in Fig. 6a) followed the observed densities rather well up to the early 1990s. Starting from 1997, observed adult densities lagged far behind expected values till around 2010. This was the period of low survival (Fig. 3), starting in 1996 at one and in 1997 at four sampling sites (Fig. 3b). Expected adult densities at constant recruitment and real survival (open points in Fig. 6b) followed the observed densities rather well up to 2005, though the peak of observed numbers around 1994 (due to the extraordinarily successful recruitment in 1991: Fig. 2) was missed. Starting from 2006, observed densities lagged behind expected values. This was the period of low recruitment, starting with the small cohort born in 2004 (Fig. 2) that reached adult age in 2006.

Summarizing: for the period up to 1992, both models resulted in realistic expectations of the size of the adult population. It was a period of relatively high stability in both recruitment and survival (Figs. 2, 3). The first serious deviation (by more than a factor two) occurred in 1993, when the constant-recruitment model started to expect too low numbers of adults for some years (Fig. 6b), originating mostly from the highly successful 1991-recruitment. The constant-survival model (Fig. 6a) rightly showed the increase in adult numbers in 1993. The following substantial deviation started around 1997, when the constant-survival model overestimated the adult population size for a long period (Fig. 6a). For the first half of this period (up to 2005), the constant-recruitment model yielded a realistic number of adults (Fig. $6 \mathrm{~b}$ ). Thus, the declining and finally low observed densities of adults in the 1997-2005 period were fully due to low adult survival. After 2005, the deviations for the constant-recruitment model were most conspicuous (Fig. 6b), showing consistently higher expected numbers. This was the period of reduced recruitment (Fig. 2). As the expected numbers of the constant-survival model were too high as well for this period (Fig. 6a), we conclude that both reduced recruitment and reduced survival were causes of the low adult densities in the last decade.

\section{Relationship between size of adult stock and success of recruitment}

In the above, we showed how the size of adult stocks was governed by annual recruitment and subsequent survival rates. The observed declining trend of the adult population size after the mid-1990s could largely be explained by declines of annual survival rates. Only after the mid2000s, the observed adult numbers lagged behind values expected on the base of only variation in survival (Fig. 6b), pointing to seriously reduced recruitment for the last 10 years. The question then arises, whether this recruitment reduction might have originated from too small adult stocks to ensure sufficient annual reproduction.

The stock-recruitment curve for the Balgzand L. balthica population was curvilinear (Fig. 7). At low adult 

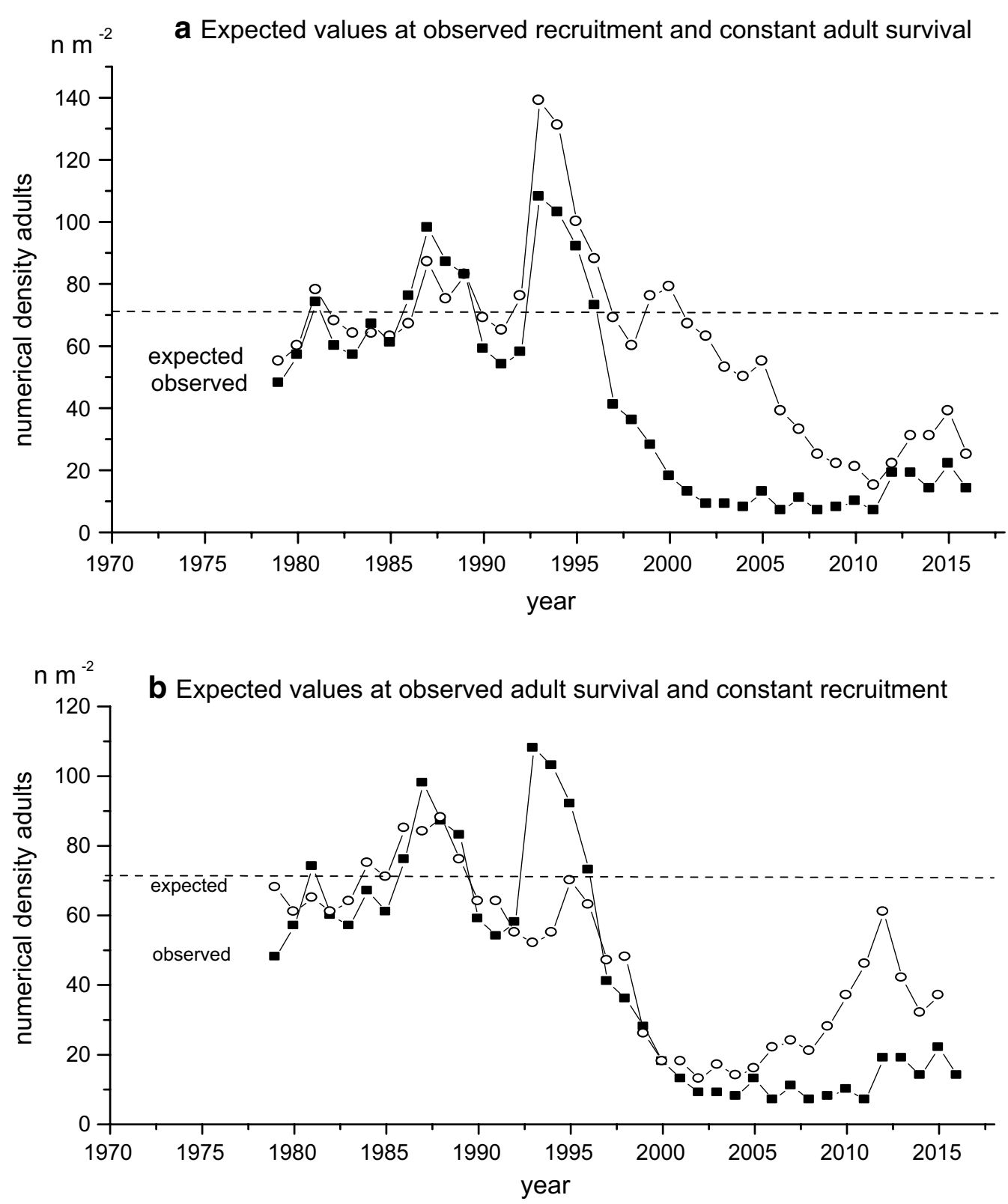

Fig. 6 Long-term data series of (solid points) observed and (open points) expected numerical densities ( $\mathrm{nm}^{-2}$ ) of adult (age at least 2.3 years) Limecola balthica on Balgzand. Expected densities calculated on the base of a observed densities of each cohort at an age of 1.3 years and supposed constant annual survival rates of $65 \%$ year ${ }^{-1}$ in subsequent years, and $\mathbf{b}$ observed annual survival rates and supposed densities of 32 ind $\mathrm{m}^{-2}$ of each cohort at an age of 1.3 years. The dashed horizontal lines show expected densities when both initial density and annual survival were constant at the above values

densities (up to a few tens of adults $\mathrm{m}^{-2}$ ), recruit densities rose rapidly with adult numbers (from around 10 to around $100 \mathrm{~m}^{-2}$ in 0.3-year-olds and to around 20 in 1.3-year-olds). At higher adult densities $\left(>50 \mathrm{~m}^{-2}\right)$, recruit abundance no longer changed consistently with adult numbers, instead more or less stabilizing at a high level (generally between 100 and 1000 recruits $\mathrm{m}^{-2}$ of 0.3 -yearolds and between 20 and $70 \mathrm{~m}^{-2}$ of 1.3 -year-olds). The best fitting 2nd order polynomials for the 40-41 data pairs of annual recruitment $\mathrm{R}$ and adult density $\mathrm{D}$ were: 

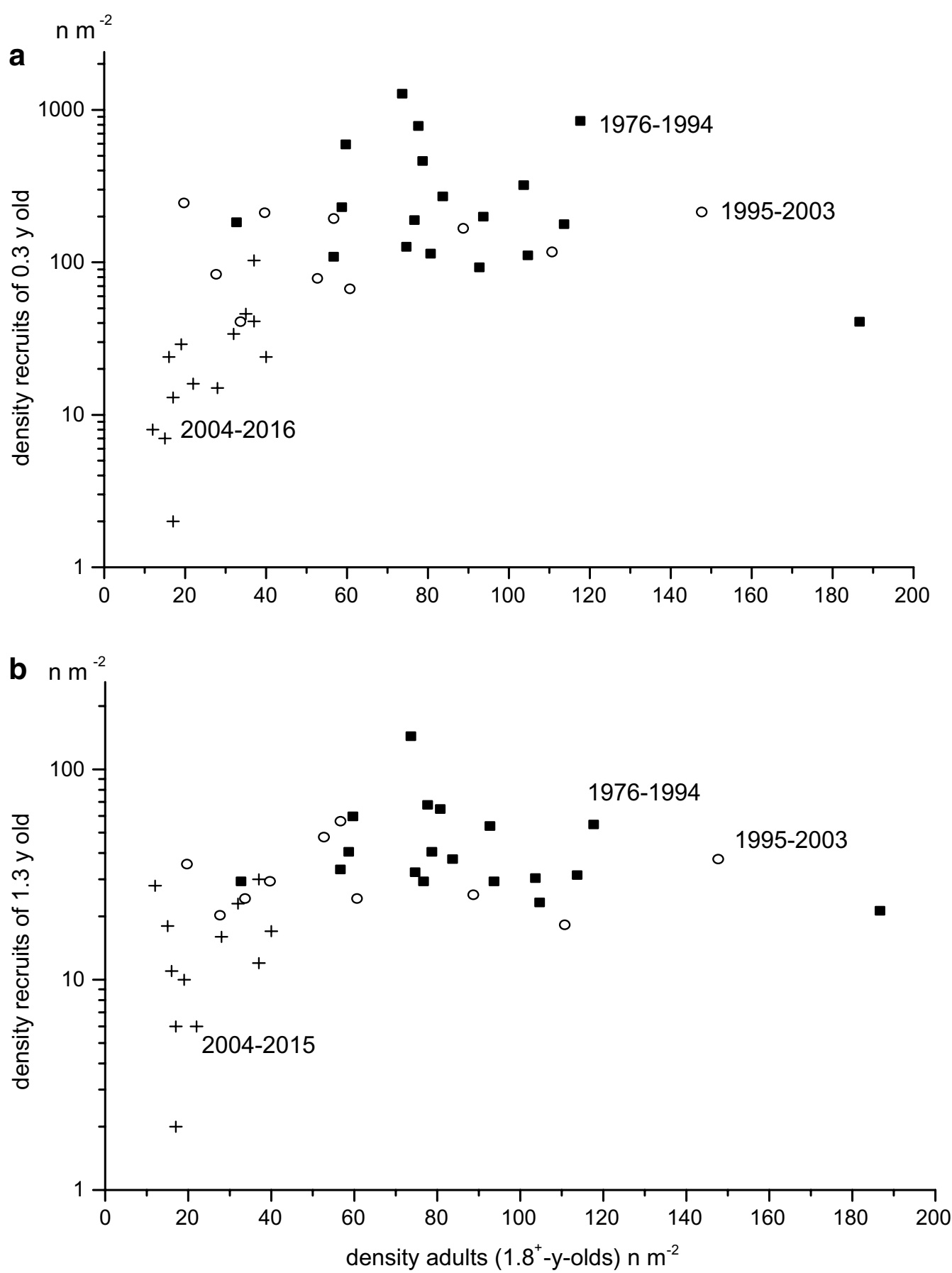

Fig. 7 Limecola balthica. Relationship between size of adult stock ( $\mathrm{nm}^{-2}$ of individuals of at least 1.8 years old, as assessed in late winter) and abundance of recruits $\left(\mathrm{nm}^{-2}\right.$, plotted on ${ }^{10} \mathrm{log}$ scale) that were born in the subsequent summer, as assessed in $\mathbf{a}$ the subsequent summer, after about 0.3 year of benthic life, and $\mathbf{b} 1$ year later at an age of 1.3 years. Means of data collected at 15 sampling sites. One point for each of 41 cohorts; periods of birth indicated: (solid squares) 1976-1994, (open circles) 1995-2003, and (crosses) 2004-2015 (or 2016) 
(for 0.3-year-old recruits) ${ }^{10} \log \mathrm{R}$

$$
\begin{aligned}
= & 0.76+0.033 \mathrm{D}-0.00015 \mathrm{D}^{2} \\
& \left(\mathrm{r}^{2}=0.57, \mathrm{n}=41, p<0.0001\right), \text { and }
\end{aligned}
$$

(for 1.3-year-old recruits) ${ }^{10} \log \mathrm{R}$

$$
\begin{aligned}
= & 0.87+0.015 \mathrm{D}-0.00007 \mathrm{D}^{2} \\
& \left(\mathrm{r}^{2}=0.40, \mathrm{n}=40, p<0.0001\right) .
\end{aligned}
$$

The increasing and stable parts of the stock-recruitment relationship represented different multi-year periods, indicated by different symbols in Fig. 7. Up to and including 1994 (solid squares), recruitment appeared to be independent of the size of the adult stock, which amounted to densities of $>50 \mathrm{~m}^{-2}$. During some subsequent years, up to and including 2003 (open circles), recruitment remained at a high level in most years, at adult densities of mostly between about 20 and $100 \mathrm{~m}^{-2}$. After 2003 (crosses), recruitment was reduced in nearly all years. In the case of 0.3 -year-olds (Fig. 7a), recruitment significantly $\left(\mathrm{r}^{2}=0.49, \mathrm{n}=13, p<0.01\right)$ increased with adult abundance (from about 10 to about $40 \mathrm{~m}^{-2}$ ). Thus, the increasing part of the stock-recruitment relationship was restricted to the last 13 years of the observations, when adult densities had declined to values of $<40 \mathrm{~m}^{-2}$.

\section{Discussion}

\section{Changes in stock size}

The abundance of the L. balthica population at Balgzand declined dramatically, roughly decimated, between the 1980 s/early 1990 s and the 2000s. A similarly strong decline (from about 100 to $<10 \mathrm{~m}^{-2}$ ) was reported in [2] for a vast area in the western Dutch Wadden Sea between the late 1990s to the mid-2000s. Changes in the size of the L. balthica population all over the Dutch Wadden Sea by collating data from the "grey" literature are reported in [13]. Everywhere in the Dutch Wadden Sea, adult densities became extremely low in the course of the 2000s after much higher abundances in earlier years. Balgzand thus appears to be a representative area for population changes over much wider areas and a suitable area for studying underlying causes.

\section{Survival and recruitment}

The most radical change during the $>40$ year monitoring period was the sudden severe decline of adult survival that started in the mid-1990s, from an average of around $70 \%$ to around $20 \%$ year $^{-1}$. The decline started at one site and gradually spread within 5 year to all sampling sites (Fig. 4). Pending further research, the spread resembled the horizontal transmission of a contagious disease, such as observed in soft-shell clams [14].

Within 5 years, the size of the adult population had declined from a mean of about 70 individuals $\mathrm{m}^{-2}$ for the pre-reduction period to about $10 \mathrm{~m}^{-2}$ (Fig. 6a). Despite increasing survival after 2005, the level of adult densities remained low. This was caused by reduced recruitment (Fig. 6b), probably as a consequence of too small adult stocks (Fig. 7). Therefore, we think that the low final (post-2005) levels of adult numbers and recruitment success might have been indirect consequences of the earlier reductions of adult survival.

We do not think that the lower levels of population size, survival and recruitment had anything to do with shellfish fishery. In the Balgzand area, fishing was forbidden starting from 1993 and the last year of intensive fishing was $1990[15,16]$. The described declines in the L. balthica population started only around 1995. It is remarkable that the highest recruitment of the 44-year period occurred in 1991 immediately after the year with the most intensive fishery. The highest abundance of adults was observed in 1993 and was built up within the period fishery was still allowed.

Some caution is warranted in the interpretation of the stock-recruitment relationship presented in Fig. 7: the low recruitments observed in the 2004-2015 period were not necessarily a consequence of the small adult stocks. Maybe, both adult stock as well as recruitment were negatively affected by an unknown environmental factor (such as a disease) acting during this period. Unfortunately, no small stocks were found outside this period and thus no recruitment data are available for small stocks before the commencement of the low adult survival.

\section{Climate effects}

The observed negative effects of rising water temperatures on both recruitment and survival were less drastic (Fig. 5; [7]) than the actual declines of recruitment and survival. Therefore, they could not explain the strong reductions in survival (starting around 1995) and recruitment (starting around 2004).

Rising water temperatures as a consequence of climate change might be important for future developments of the L. balthica population in the Wadden Sea. At the present water temperatures in winter, and without special incidents, we might expect recruitment levels of around $200 \mathrm{~m}^{-2}$ (0.3-year-olds) or $30 \mathrm{~m}^{-2}$ (1.3-year-olds) and survival levels of around $60 \%$ year $^{-1}$. Such values would result in adult $\left(2.3^{+}\right.$-year-olds $)$densities of around $45 \mathrm{~m}^{-2}$, being $63 \%$ of the earlier (1980s and early 1990s) level of $71 \mathrm{~m}^{-2}$. Thus, expected climate effects would be far smaller than the observed decline in adult numbers between 1995 and 2005. The present recovery of adult 
numbers to about $20 \mathrm{~m}^{-2}$, then, would be roughly halfway the final level expected for the near future. Recruitment nor survival have yet recovered to the rather stable earlier (1973-1995) levels.

\section{Conclusions}

During the first half of the 44 years of observation, the population of $L$. balthica on Balgzand was remarkably stable with high levels of annual recruitment and adult survival. The subsequent decline of the population size was primarily due to the severely reduced survival rates that started to occur in 1995 in a limited subarea, but soon spread over the entire Balgzand area to reach the last subarea 5 year later. As a consequence of the declining adult stock size, recruitment became low starting from 2004. The warming climate had a small but consistent negative effect on both recruitment and adult survival. So far, there was hardly any recovery as both recruitment and survival remained at levels lower than found for the initial stable period.

\section{Authors' contributions}

JJB did most of the writing, RD most of the data collection, JD assisted and contributed ideas. All authors read and approved the final manuscript.

\section{Author details}

${ }^{1}$ Royal Netherlands Institute for Sea Research, P.O. Box 59, 1790 AB Den Burg, Texel, The Netherlands. ${ }^{2}$ Utrecht University, Utrecht, The Netherlands.

\section{Acknowledgements}

We are grateful to a number of assistants who helped in the field work.

\section{Competing interests}

The authors declare that they have no competing interests.

\section{Availability}

Data are stored in the data base at NIOZ: Royal Netherlands Institute for Sea Research, P.O. Box 59, 1790 AB Den Burg, Texel, The Netherlands.

\section{Consent}

Not applicable.

\section{Ethics}

Not applicable.

\section{Funding}

Part of the work was financially supported by the National Institute for Coastal and Marine Management (RWS/RIKZ).

\section{Publisher's Note}

Springer Nature remains neutral with regard to jurisdictional claims in published maps and institutional affiliations.

Received: 29 May 2017 Accepted: 2 October 2017

Published online: 10 October 2017
References

1. Zwarts L, Wanink JH. How the food supply harvestable by waders in the Wadden Sea depends on the variation in energy density, body weight, biomass, burying depth and behavior of tidal-flat invertebrates. Neth J Sea Res. 1993:31:441-76.

2. Compton TJ, et al. Burrowing behavior of a deposit feeding bivalve predicts change in intertidal ecosystem state. Frontiers Ecol Evol. 2016;4(19):1-9.

3. Jensen KT. Macrozoobenthos on an intertidal mudflat in the Danish Wadden Sea: comparisons of surveys made in the 1930s, 1940s and 1980s. Helgol Meeresunters. 1992;46:363-76.

4. Schückel U, Kröncke I. Temporal changes in intertidal macrofauna communities over eight decades: a result of eutrophication and climate change. Estuar Coast Shelf Sci. 2013;117:210-8

5. Beukema JJ, Dekker R. Variability in predator abundance links winter character and bivalve recruitment: correlative evidence from long-term data in a tidal flat. Mar Ecol Prog Ser. 2014;513:1-15.

6. Beukema JJ, Meehan BW. Latitudinal variation in linear growth and other shell characteristics of Macoma balthica. Mar Biol. 1985;90:27-33.

7. Beukema JJ, Dekker R, Jansen JM. Some like it cold: populations of the tellinid bivalve Macoma balthica (L.) suffer in various ways from a warming climate. Mar Ecol Prog Ser. 2009;384:135-45.

8. Van Aken HM. Variability of the water temperature in the western Wadden Sea on tidal to centennial scales. J Sea Res. 2008:60:227-34.

9. Philippart CJM, Van Aken HM, Beukema JJ, Bos OG, Cadée GC, Dekker R. Climate-related changes in recruitment of the bivalve Macoma balthica. Limnol Ocean. 2003:48:2171-85.

10. Piersma T, Koolhaas A, Dekinga A, Beukema JJ, Dekker R, Essink K. Longterm indirect effects of mechanical cockle-dredging on intertidal bivalve stocks in the Wadden Sea. J Appl Ecol. 2001;38:976-90.

11. Beukema JJ, Cadée GC. Local differences on macrozoobenthic response to enhanced food supply caused by mild eutrophication in a Wadden Sea area: food is only locally a limiting factor. Limnol Oceanogr. 1997:42:1424-35.

12. De Boer M. Uitwisseling wadwater Balgzand. Waterloopkundig onderzoek mei 1977. Nota 78H005. Rijkswaterstaat, Studiedienst Hoorn 1978;1-29.

13. Beukema JJ, Dekker R, Drent J. Parallel changes of Limecola (Macoma) balthica populations in the Dutch Wadden Sea. Mar Ecol Prog Ser (in press).

14. Metzger MJ, Reinisch C, Sherry J, Goff SP. Horizontal transmission of clonal cancer cells causes leukemia in soft-shell clams. Cell. 2015;161:255-63.

15. Beukema JJ. Increased mortality in alternative bivalve prey during a period when the tidal flats of the Dutch Wadden Sea were devoid of mussels. Neth J Sea Res. 1993;31:395-406.

16. Beukema JJ, Cadée GC. Consequences of the sudden removal of nearly all mussels and cockles from the Dutch Wadden Sea. Mar Ecol. 1996;17:279-89.
Submit your next manuscript to BioMed Central and we will help you at every step:

- We accept pre-submission inquiries

- Our selector tool helps you to find the most relevant journal

- We provide round the clock customer support

- Convenient online submission

- Thorough peer review

- Inclusion in PubMed and all major indexing services

- Maximum visibility for your research

Submit your manuscript at www.biomedcentral.com/submit 